\title{
UMA ANÁLISE CONTRASTIVA DOS BERGOGLISMOS EM CORPUS DE DISCURSOS DO PAPA FRANCISCO
}

\author{
A CONTRASTIVE ANALYSIS OF BERGOGLISMS IN POPE FRANCIS SPEECH \\ CORPUS
}

\section{UN ANALISIS CONTRASTIVO DE LOS BERGOGLISMOS EN CORPUS DE DISCURSOS DEL PAPA FRANCISCO}

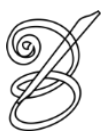 \\ Ariel NOVODVORSKI* \\ Universidade Federal de Uberlândia, Brasil \\ Hellen Betin MIRANDA** \\ Universidade Federal de Uberlândia, Brasil
}

\begin{abstract}
Resumo: Em 2013, Jorge Bergoglio, argentino, foi eleito Papa da Igreja Católica de Roma. O interesse por sua personalidade cativante, para além do fato de ser o primeiro pontífice latino-americano, ganhou preponderância, desde então, despertando a curiosidade em torno dos chamados bergoglismos - fala peculiar do Papa Francisco. O objetivo do presente trabalho é analisar marcas de Avaliatividade nos discursos papais oficiais em língua espanhola e nas respectivas traduções para o português. O site oficial do Vaticano disponibiliza, entre outros textos, os discursos papais em diversas línguas. Assim, este trabalho compilou desse site os discursos feitos em países de língua espanhola e suas respectivas traduções para a língua portuguesa. A partir desse corpus, com subsídios da Linguística de Corpus (BERBER SARDINHA, 2004) e as ferramentas do programa WordSmith Tools 6.0 (SCOTT, 2012), foram analisados aspectos de Avaliatividade em torno dos bergoglismos em ambas as línguas. Para isso, a teoria da Avaliatividade (MARTIN; WHITE, 2005) norteou as análises, por meio dos significados dos subsistemas da Atitude (Julgamento, Afeto e Apreciação). Por outro lado, os neologismos foram observados a partir da classificação de Alves (1990). Com esse arcabouço teórico e um quadro metodológico inspirado em Novodvorski (2008; 2013), além das ferramentas da Linguística de Corpus, este trabalho analisou a formação dos neologismos papais e as marcas de Avaliatividade impressas pelo Papa nessas construções neológicas (bergoglismos), comparando-as com as traduções para a língua portuguesa. Para alcançar tais propósitos, além da compilação do corpus de estudo, também se fez oportuna a compilação de um corpus de apoio, com matérias jornalísticas sobre o Papa e, principalmente, sobre os referidos bergoglismos. Espera-se que esta pesquisa contribua para os Estudos da Tradução e da Neologia baseados em corpus, mais especificamente sob a visão da teoria da Avaliatividade e dos recursos da Linguística de Corpus, visto que os procedimentos adotados neste estudo também poderão ser replicados em outros corpora. A combinação teóricometodológica e a escolha do corpus paralelo espanhol/português mostraram-se produtivas.
\end{abstract}

Palavras-chave: Neologia. Avaliatividade. Estudos da Tradução. Linguística de Corpus. Bergoglismos.

Abstract: In 2013, Jorge Bergoglio, from Argentina, was elected Pope of the Catholic Church of Rome. The interest in his captivating personality, in addition to be the first Pope of Latin America, has gained preponderance since then, arousing curiosity around the so-called bergoglisms - speaks peculiarly of Pope Francis. The objective of the present work is to analyze the marks of Appraisal in the official papal discourses in Spanish language and in the respective translations into Portuguese. The Vatican's official website makes available, among other texts, the papal discourses translated into various languages. Thus, this work has compiled from this site the discourses made by Pope Francis in Spanish-speaking countries and their respective translations into Portuguese. From this corpus, with subsidies from Corpus Linguistics (BERBER SARDINHA, 
2004) and the tools of the WordSmith Tools 6.0 program (SCOTT, 2012), aspects of Appraisal were analyzed around the bergoglisms in both languages. For this, the theory of Appraisal (MARTIN; WHITE, 2005) guided the analyses, through the meanings of the subsystems of Attitude (Judgement, Affect and Appreciation). On the other hand, the neologisms were observed from the classification of Alves (1990). With this theoretical framework and a methodological framework inspired by Novodvorski (2008; 2013), in addition to the tools of Corpus Linguistics, this work analyzed the formation of papal neologisms and the marks of Appraisal printed by the Pope in these neological constructions (bergoglisms), comparing them with the translations into the Portuguese language. To achieve these purposes, in addition to the compilation of the study corpus, it was also appropriate to compile a support corpus, with journalistic articles about the Pope and, especially, about the bergoglisms mentioned. It is hoped that this research will contribute to the corpus-based Studies of Translation and Neology, more specifically from the perspective of the theory of Appraisal and the resources of Corpus Linguistics, since the procedures adopted in this study can also be replicated in other corpora. The theoreticalmethodological combination and the choice of the Spanish/Portuguese parallel corpus have proved to be productive.

Keywords: Neology. Appraisal. Translation Studies. Corpus Linguistic; Bergoglisms.

Resumen: Jorge Bergoglio, oriundo de Argentina, fue elegido Papa de la Iglesia Católica Romana en 2013. El interés por su cautivadora personalidad, además del hecho de ser el primer pontífice latinoamericano, ha ido ganando protagonismo desde entonces, despertando curiosidad en torno a los llamados bergoglismos - léxico característico en el habla del Papa Francisco. El objetivo del presente trabajo es analizar las marcas de Valoración en los discursos oficiales del Papa en lengua española y en las respectivas traducciones al portugués. El sitio web oficial del Vaticano pone a disposición, entre otros textos, los discursos papales traducidos a diferentes idiomas. Por lo tanto, este trabajo ha recopilado a partir de ese sitio los discursos del Papa Francisco proferidos en español en los países de habla hispana y sus respectivas traducciones al portugués. A partir de ese corpus, con subsidios de la Lingüística de Corpus (BERBER SARDINHA, 2004) y de las herramientas del programa WordSmith Tools 6.0 (SCOTT, 2012), se analizaron aspectos de Valoración, en torno de los bergoglismos en ambos idiomas. Para ello, la teoría de la Valoración (MARTIN; WHITE, 2005) guió los análisis, a través de los significados de los subsistemas de Actitud (Juicio, Afecto y Apreciación). Por otro lado, los neologismos se observaron desde la clasificación de Alves (1990). Con este marco teórico y un marco metodológico inspirado en Novodvorski (2008; 2013), además de las herramientas de la Lingüística de Corpus, este trabajo analizó la formación de neologismos papales y las marcas de valoración impresas por el Papa en esas construcciones neológicas (bergoglismos), comparándolas con las traducciones al portugués. Para lograr estos fines, además de la recopilación del corpus de estudio, también fue conveniente recopilar un corpus de apoyo, con artículos periodísticos sobre el Papa y, especialmente, sobre los mencionados bergoglismos. Se espera que esta investigación contribuya a los Estudios de Traducción y de la Neología basados en corpus, más específicamente desde la perspectiva de la teoría de la Valoración y los recursos de la Lingüística de Corpus, ya que los procedimientos adoptados en este estudio también podrán ser replicados en otros corpus. La combinación teórico-metodológica y la elección del corpus paralelo español/portugués resultó ser productiva.

Palabras clave: Neología. Valoración. Estudios de la Traducción. Lingüística de Corpus. Bergoglismos.

RECEBIDO EM: 15/02/2019

ACEITO EM: 10/08/2019

PUBLICADO EM: 10/2019

NOVODVORSKI, Ariel; MIRANDA, Hellen Betin. Uma análise contrastiva dos bergoglismos em corpus de discursos do Papa Francisco. Belas Infiéis, Brasília, v. 8, n. 4, p. 91-109, 2019. 


\section{Introdução}

pós a eleição de Jorge Bergoglio, natural da Argentina, como Papa da Igreja
Católica de Roma em 2013, começam a circular nos meios de informação os
chamados bergoglismos, modo de falar do Papa, neologismos criados pelo próprio Bergoglio. Essa novidade no linguajar papal foi noticiada por vários jornais, como La Gaceta ${ }^{1}$ e La Nación ${ }^{2}$, da Argentina, tratando diretamente os bergoglismos como um léxico que impacta e tem chamado a atenção de todos. A popularidade da figura do Papa Francisco resultou na produção de uma série pela Netflix, de um filme e de uma minissérie pelo canal History Channel, em parceria com a Anima Films.

Com a motivação dessa novidade, foi compilado um corpus com discursos papais das viagens a países que têm o espanhol como idioma oficial. Em contato com o objeto de pesquisa, investigamos a formação dos neologismos denominados bergoglismos e suas marcas de Avaliatividade, para contrastá-los, posteriormente, com suas respectivas traduções. O conjunto de procedimentos metodológicos aplicados a uma pesquisa em Neologia, Avaliatividade e Tradução entre o par espanhol-português, a partir do suporte de ferramentas e recursos próprios da Linguística de Corpus, também foi objeto de reflexão.

A partir dessas motivações, elaboramos alguns questionamentos: a) Como estariam formados os chamados bergoglismos? b) Quais seriam as marcas de Avaliatividade em torno dos bergoglismos? c) Qual seria o tratamento dado nas respectivas traduções? Assim, os objetivos centrais do presente trabalho são identificar e analisar a formação e as traduções dos bergoglismos, além de suas marcas de Avaliatividade, num corpus paralelo espanhol/português, composto pelos discursos do Papa Francisco.

Para o tratamento do corpus de estudo, recorremos aos subsídios da Linguística de Corpus (BERBER SARDINHA, 2004), com as ferramentas do programa WordSmith Tools, 6.0 (SCOTT, 2012). A teoria da Avaliatividade (MARTIN; WHITE, 2005) amparou o estudo do Julgamento, do Afeto e da Apreciação em torno dos bergoglismos, norteando os significados por meio do subsistema da Atitude. Para a compreensão das formações neológicas, baseamo-nos no estudo e nas classificações de Alves (1990). A análise das traduções foi realizada a partir de Hurtado Albir (2008).

Para além desta seção introdutória, compõem este artigo uma discussão teórica, uma seção metodológica em que é apresentado também o corpus de estudo, a análise e discussão dos dados, além das considerações finais e das referências bibliográficas. 


\section{Percurso teórico}

A consideração de fenômenos lexicais, sintáticos e semânticos usuais, principalmente na língua falada, não estabelece uma delimitação entre "certo" e "errado". Nesse sentido, a linguística descritiva subsidia a percepção e a análise da língua realizada, em uso, nos diversos contextos comunicativos, revelando os usos aceitos pela sociedade. Além disso, essa área do saber auxilia na neutralização da nossa subjetividade, por meio do exame de corpora autênticos, colhidos de usos reais, uma vez que tem como objetivo o "estudo da organização interna dos enunciados linguísticos de cada língua, tanto no que diz respeito à forma quanto no que diz respeito ao seu significado (gramática), além das relações entre forma e significado" (PERINI, 2006, p. 18). Assim, a compreensão das escolhas papais, no que tange à criatividade lexical e à sintaxe, está determinada pela relação entre as palavras e o conhecimento de mundo. Esta seção teórica tratará questões sobre Neologia, Avaliatividade, Estudos da Tradução e Linguística de Corpus.

A vivacidade da língua pode ser apreciada, justamente, pelo fator criatividade de seus usuários, nos mais diversos contextos comunicativos. É nessa situação de uso que surgem os 94 neologismos: a criação de novos léxicos ou significados fomentados pelo momento histórico ou por necessidades sociais (ALVES, 1990). A formação desses fenômenos derivam de ordem fonética, fonológica, morfológica, sintática, semântica ou lexical, gerando neologismos dos tipos: onomatopaicos ("xou"3, referente ao show da Xuxa); de derivação prefixal (neopelagianismo); derivação sufixal (misericordiado); derivação parassindética (ensantada); composição coordenativa (cariñoterapia); de ordem semântica (encorsertar); verbal (primerear); empréstimo (selfie); entre outros tipos de neologismos. Essas categorias serão desenvolvidas na seção de análises, durante a descrição das formas neológicas feitas do Papa Francisco, identificadas no corpus de estudo.

Para a compreensão do lugar ocupado pela Avaliatividade, no marco dos estudos da Linguística Sistêmico-Funcional (LSF), cabe destacar que, nos enunciados linguísticos da fase adulta, as funções desempenhadas pelo falante com a linguagem são complexas, em cada ato linguístico convergem simultaneamente mais de uma função. Halliday (1978) postula três macrofunções, que posteriormente denominará metafunções, as quais norteiam qualquer enunciação, a saber: ideacional, interpessoal e textual.

A metafunção ideacional realiza na linguagem a experiência exterior (de mundo) ou interior (da consciência), e possui os componentes experiencial e lógico. A metafunção interpessoal é o modo de relação com outros falantes, por meio da linguagem, é a 
manifestação pessoal e a interação social, envolvendo o modo (imperativo, subjuntivo ou indicativo) e a modalidade (expectativa do interlocutor), e abarcando as interações entre os atores sociais e as atribuições de papéis que deles são esperados, ligando-se, assim, à pragmática (HALLIDAY, 1978). Pela função textual, a língua se torna um texto, ou seja, "é o mecanismo linguístico que liga umas às outras as seleções significativas que derivam das várias funções da língua, e as realiza numa forma estrutural unificada" (HALLIDAY, 1978).

O sistema da Avaliatividade é um dos componentes que integram a semântica do discurso, no plano da metafunção interpessoal, junto aos sistemas de Envolvimento e Negociação. Martin e White (2005), a partir dos preceitos da LSF, desenvolveram o sistema da Avaliatividade.

O princípio que perpassa o sistema da Avaliatividade sustenta que um falante/escritor, ao se manifestar, oralmente ou por escrito, revela mais do que um conteúdo estritamente linguístico. O enunciado revela suas crenças, cultura, avaliações, personalidade. Isto é, as categorias que integram o sistema da Avaliatividade oferecem recursos para investigar como as escolhas linguísticas e o discurso podem revelar tais aspectos do indivíduo, em relação a suas opiniões e sentimentos.

Inicialmente, White (2000) começou a investigar em quais contextos, com quais meios linguísticos e com quais objetivos retóricos os escritores transmitem os seus posicionamentos e seus julgamentos. O autor define o sistema de Avaliatividade como a ciência que se ocupa da linguagem, dos recursos linguísticos que expressam, negociam e naturalizam certas posições intersubjetivas em textos orais ou escritos.

A Avaliatividade é dividida em três subsistemas: Atitude, Engajamento e Gradação. Neste trabalho, ocuparemo-nos apenas da Atitude. Esta é referente aos valores que os falantes emitem em seus julgamentos, suas apreciações ou em suas respostas emocionais e afetivas. Cada um desses sistemas se ramifica em novas possibilidades de escolha, estabelecendo uma rede de (sub)sistemas. O sistema da Atitude se subdivide em Afeto, Julgamento e Apreciação, dimensões que se relacionam, respectivamente, à emoção, à ética e à estética, e que constituem escolhas feitas pelos falantes para comunicar suas avaliações. Em outras palavras, quando se fala/escreve sobre algo, no plano interpessoal, manifestamos a Atitude por meio do Afeto, do Julgamento ou da Apreciação (WHITE, 2000; MARTIN; WHITE, 2005).

O Afeto diz respeito aos sentimentos positivos ou negativos do emissor, como felicidade/infelicidade, segurança/insegurança, satisfação/insatisfação, desejo/medo. No Julgamento, o falante emite avaliações a respeito do comportamento e caráter das pessoas. Os 
Julgamentos podem ser de Estima social (envolvem valores sociais) ou de Sanção social (geralmente com implicações legais). A Apreciação, por fim, expõe avaliações sobre coisas ou fenômenos da realidade, por meio da Reação (quanto atrai a atenção ou de que maneira impacta), da Composição (equilíbrio das coisas, proporção, detalhe, complexidade) ou da valoração (importância social).

A seguir, ilustramos alguns exemplos desses subsistemas retirados do nosso corpus de estudo:

Quadro 1 - Exemplos de marcas de Atitude no corpus

\begin{tabular}{|c|l|l|}
\hline Subtipo & \multicolumn{1}{|c|}{ Corpus espanhol (TO) } & \multicolumn{1}{c|}{ Corpus português (TT) } \\
\hline $\begin{array}{c}\text { Afeto: } \\
\text { felicidade }\end{array}$ & $\begin{array}{l}\text { Estoy contento de poder } \\
\text { encontrarlos. }\end{array}$ & $\frac{\text { Estou feliz por vos poder }}{\text { encontrar. }}$ \\
\hline $\begin{array}{c}\text { Julgamento: } \\
\text { estima social }\end{array}$ & $\begin{array}{l}\text { Dios que es sólo y pleno } \\
\text { presente. }\end{array}$ & $\begin{array}{l}\text { Deus que é o único e pleno } \\
\text { presente. }\end{array}$ \\
\hline $\begin{array}{c}\text { Apreciação: } \\
\text { reação }\end{array}$ & Su mirada materna. & Seu olhar materno. \\
\hline
\end{tabular}

Elaboração: Novodvorski e Miranda

Desse modo, o sistema da Avaliatividade, em particular o subsistema da Atitude, oferece o suporte necessário para o presente trabalho, a partir do momento em que entendemos a relação imbricada entre linguagem e contexto social, a manifestação do sistema linguístico no texto, o modo como o locutor/escritor se expressa, a (re)construção das palavras e seus potenciais de significado e como cada traço revela a cultura e a personalidade que estão por trás do discurso.

Considerando que o corpus de estudo está composto por textos em língua espanhola e portuguesa, para o estudo contrastivo das traduções, tomamos como base para a interpretação das traduções Hurtado Albir (2008). A autora apresenta a Tradução como uma habilidade, um "saber fazer", ou seja, um saber operacional textual durante todo o processo de traduzir, para resolução dos problemas tradutórios, ao longo de um texto. Por outro lado, a Tradutologia é a ciência que estuda a prática tradutora.

Para indagação do corpus e análise contrastiva das escolhas tradutórias, é importante o estudo das classificações e definições do fazer tradutório, que perpassam três planos: o léxico, a organização (morfologia e sintaxe) e a mensagem. A seguir, listamos algumas das técnicas propostas por Hurtado Albir (2008, p. 269-271), que servem de suporte ao estudo do corpus: 
- Adaptação: substituição de um elemento cultural por outro;

- Amplificação: introdução de informações não formuladas no texto original, como referências, notas, etc.;

- Decalque: tradução literal de uma palavra estrangeira;

- Descrição: substituição de um termo ou expressão por sua descrição/explicação;

- Elisão: omissão de um elemento presente no texto original;

- Empréstimo: manutenção da palavra estrangeira no texto traduzido;

- Equivalente cunhado: uso de uma expressão da língua de chegada equivalente à expressão do texto original;

- Generalização: uso de um termo mais geral ou neutro;

- Modulação: mudança de ponto de vista, de enfoque ou de categoria léxica e/ou estrutural;

- Tradução literal: tradução de palavra por palavra;

- Transposição: mudança de categoria gramatical (verbo por advérbio, por exemplo);

- Variação: adaptação de elementos linguísticos e paralinguísticos do texto original para o contexto da língua de chegada, para o público alvo ou gênero textual ${ }^{4}$.

Ao longo das análises, teremos a oportunidade de compreender melhor alguns desses termos, que norteiam o presente estudo.

A última área a ser abordada nesta seção teórica é a Linguística de Corpus (LC), que surgiu a partir do interesse pela descrição da linguagem, ainda no século XX. Considerada como uma abordagem ou como uma metodologia, de caráter empírico, mas também adotada por alguns estudiosos com viés teórico, a LC propicia desde o levantamento de aspectos estatísticos à observação dos usos reais da língua (GALLARDO PAÚLS, 1998).

Parodi (2010) salienta que a LC não é uma área ou ramo da Linguística (assim como a Fonologia, Semântica, Sintaxe, etc.), mas um método de investigação que pode ser empregado em seus diferentes níveis de língua e enfoques teóricos, e traz consigo o apoio de técnicas estatísticas, que dão maior representatividade ao corpus e à análise. Para isso, tanto o suporte e o processo de compilação dos corpora como o desenvolvimento e emprego de programas computacionais fazem parte inerente da LC. 
Em suma, o eixo principal é o enfoque empírico que a LC traz ao focalizar dados observáveis de modo científico, armazenados como corpora eletrônicos. Por tanto, em nosso trabalho, dispomos das ferramentas do programa computacional WordsSmith Tools, 6,0 (SCOTT, 2012), para leitura do corpus composto por textos de discursos do Papa Francisco e suas respectivas traduções ao português, realizados em países cujo idioma oficial é o espanhol.

\section{Corpus e metodologia}

A partir do interesse pela análise das traduções dos discursos do Papa Francisco, o primeiro passo consistiu na seleção dos textos para composição do corpus. Para o estudo dos pronunciamentos autênticos e na íntegra, foi verificado que o site oficial do Vaticano oferece livremente todos os discursos, homilias, cartas, mensagens, entrevistas, etc. realizados pelo Papa e disponibiliza todos os textos em até oito idiomas. O site propicia uma tradução oficial, facilitando a busca por um corpus original em espanhol e sua tradução em português 5 .

Para compilação do corpus de estudo, foram selecionados os textos oriundos dos 98 discursos realizados pelo Papa Francisco, apenas das viagens a países hispano-falantes. No site do Vaticano, ainda, foi possível conferir, nos vídeos disponibilizados, que os discursos foram feitos, de fato, em língua espanhola. A compilação foi feita manualmente, isto é, por meio do acesso aos textos desejados na página do Vaticano, salvando os textos em formato TXT para a posterior leitura com o programa WST. Para cada texto em espanhol, foi coletado também sua respectiva tradução ao português.

Os discursos papais ocorrem em reuniões ou visitas e são direcionadas a um determinado público como bispos, clero, religiosas, jovens, enfermos, etc. Todos os pronunciamentos são elaborados previamente; mas, em algumas ocasiões, o Papa emite alguns enunciados espontâneos que são informados e/ou colocados entre parênteses pelo site oficial do Vaticano.

Os textos que compõem o corpus de estudo foram salvos em formato TXT, em diferentes pastas conforme seu gênero: ângelus, discursos e homilias. Os arquivos foram nomeados com a inicial 'E', para os textos em espanhol e 'P' para as traduções em português. Também integraram a nomeação dos arquivos três primeiras letras do gênero textual 'ANG' ângelus, 'DIS' - discurso ou 'HOM' - homilia; as três primeiras letras do país visitado, como 'CUB' para Cuba ou 'MEX' para México; e, por fim, a data do pronunciamento (ano, mês e 
dia). Por exemplo, em "E.ANG.COL.2017.09.10”, temos Espanhol, Ângelus, Colômbia em 10/09/2017.

A extensão do corpus é de 85 textos autênticos (em cada língua), distribuídos assim: 5 ângelus, 57 discursos e 23 homilias do Papa Francisco, produzidos originalmente em espanhol com suas respectivas traduções. O corpus em língua espanhola totaliza uma extensão de 137.439 itens (tokens), número de palavras totais no corpus, e 13.250 formas (types), número de palavras diferentes usadas. O corpus em língua portuguesa está composto pelas respectivas traduções e totaliza 132.591 itens e 13.600 formas, como ilustrado a seguir:

Tabela 1 - Extensão do corpus de estudo

Elaboração: Novodvorski e Miranda

\begin{tabular}{l|c|c}
\hline & Itens & Formas \\
\hline Espanhol & 137.439 & 13.250 \\
\hline Português & 132.591 & 13.600 \\
\hline
\end{tabular}

A quantificação da tabela 1 foi feita com o auxílio do programa computacional WST que, após inserção de todos os textos em formato TXT, gerou esses dados separadamente para as línguas espanhola e portuguesa, por meio da ferramenta WordList.

Os textos que compõem o corpus correspondem às viagens a países hispano-falantes entre 2013 e julho de 2018. Após a compilação e limpeza do corpus (apagamento de símbolos, cabeçalhos, links, etc.), foi processado primeiramente o corpus de textos em língua espanhola no programa WST selecionado para análise. A partir disso, foi gerada uma lista de palavras com a ferramenta WordList, organizada pela frequência de ocorrência das palavras (gramaticais ou lexicais) ou por ordem alfabética. A partir dessa lista, foi feita uma leitura atenta das palavras, procedendo à exclusão das palavras que não caracterizassem neologismos, diminutivos e a fala peculiar do espanhol rio-platense. 
Figura1 - Processo de limpeza da lista de palavras

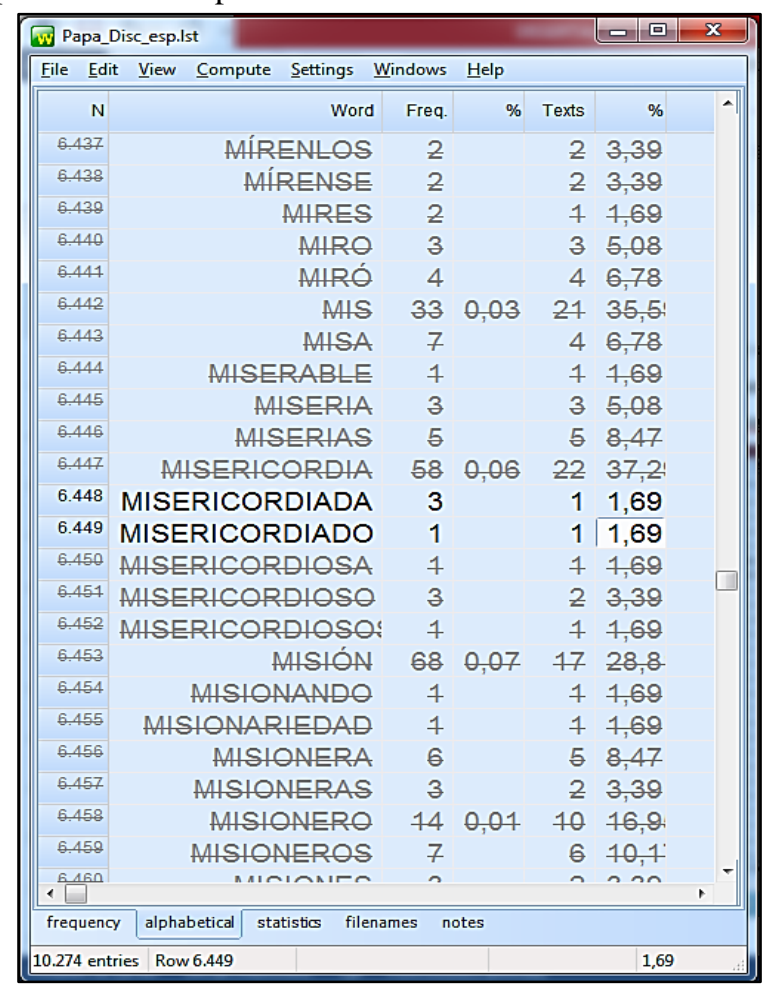

Elaboração: Novodvorski e Miranda

$\mathrm{Na}$ imagem, as palavras riscadas são as que foram deletadas, enquanto "misericordiada" e "misericordiado" foram mantidas, pois representam um neologismo criado pelo Papa, que será analisado posteriormente. Após esse procedimento de limpeza, o programa apresenta apenas as palavras selecionadas, a partir das quais será possível acessá-las em seu contexto de ocorrência, por meio da ferramenta Concordance, também integrada no WST.

Finalmente, obtida a lista com apenas as palavras selecionadas, o procedimento seguinte consistiu na análise para confirmação se, de fato, configurariam casos de bergoglismos. Os recursos utilizados para essa confirmação foi a consulta a dicionários online de língua espanhola, mas, principalmente, ao Corpus del Español ${ }^{6}$. Com a consulta aos dicionários, foi possível constatar se os vocábulos já se encontravam dicionarizados, por um lado, e se pertenceriam à região rio-platense, como "bajonear", “chamal" ou "pilcha", por exemplo: 
Figura 2 - Print da busca por bajonear no dicionário $R A E$

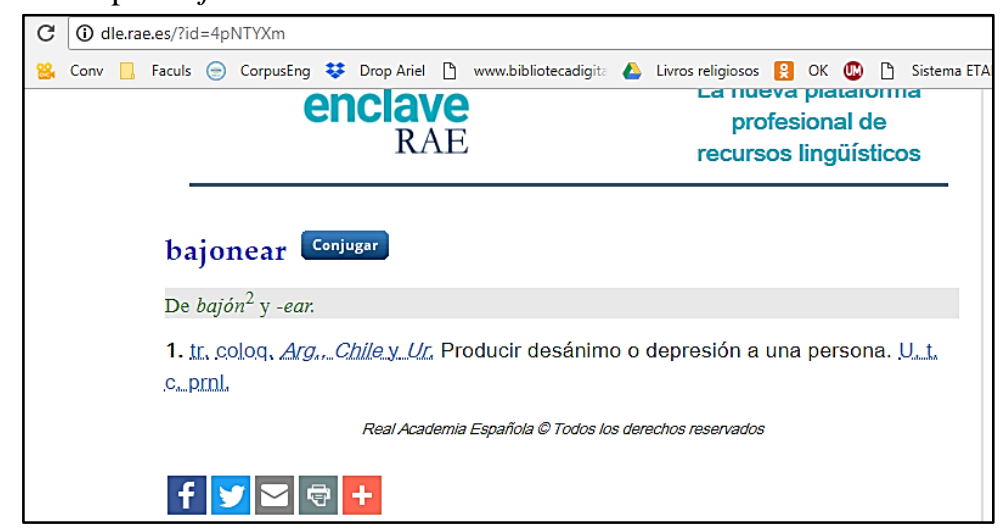

Elaboração: Novodvorski e Miranda

$\mathrm{Na}$ figura anterior, o dicionário indica que o vocábulo bajonear (dar um baixo astral) é usual na Argentina, Chile e Uruguai. Sendo assim, foi confirmada a hipótese de que o Papa Francisco utiliza um léxico característico de sua região de nascimento nos discursos. Além de regionalismos, também foram identificados nos discursos papais vocábulos coloquiais, como sabiondo (alguém que sabe muito) e remangar (com sentido de alguém se preparar para fazer algo com grande energia). Essas escolhas por vocábulos mais populares corroboram para a construção dos chamados bergoglismos, esse modo de falar característico de Jorge Bergoglio, que também inova usando neologismos próprios, não encontrados quando pesquisados nos dicionários.

Não identificadas as palavras nos dicionários, a busca foi realizada no Corpus del Español, que contém dois bilhões de palavras em espanhol, de dois milhões de páginas da web dos 21 países hispano-falantes e, também, dos Estados Unidos. Essa consulta proporcionou a frequência e origem de uso dos vocábulos buscados que, majoritariamente, corroboraram a utilização em pronunciamentos do Papa ou a comentários jornalísticos sobre ele. Contudo, apesar desse vasto e representativo corpus, houve palavras que não foram encontradas como, misericordiado ou misericordiada.

Diante dessa situação, o recurso foi recorrer à busca no Google®, para verificar a ocorrência e uso dessas palavras identificadas no corpus de estudo. A próxima figura ilustra: 
Figura 3 - Print da busca por misericordiado no Google

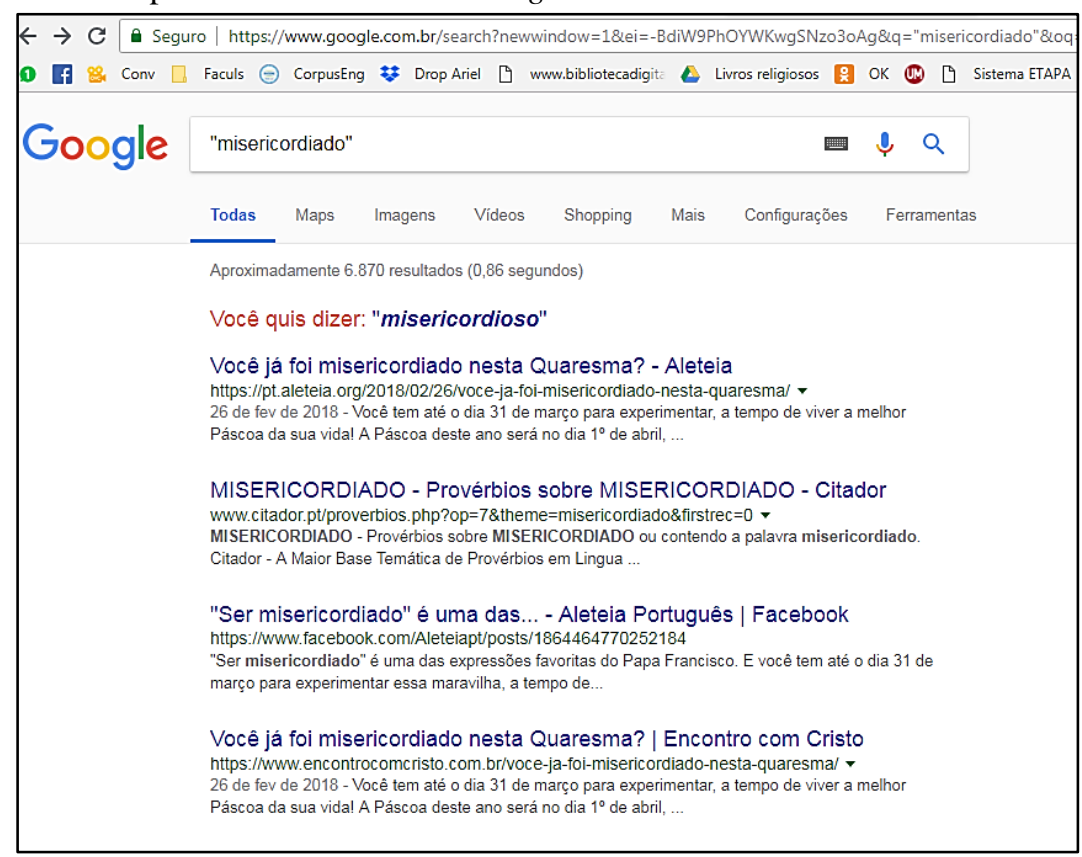

Elaboração: Novodvorski e Miranda

Assim, foi possível observar se o vocábulo seria, de fato, um neologismo, se estaria relacionado aos discursos do Papa Francisco e, também, deduzir quais seriam os significados. Geralmente, foram encontradas citações diretas do Papa, páginas católicas ensinando o significado da palavra (para que os cristãos apreendessem a mensagem papal) ou notícias comentando sobre o discurso em que Bergoglio utilizou o vocábulo.

Em suma, foi analisada cuidadosamente cada uma das palavras da lista. Mesmo as selecionadas, após a busca de seu significado e contexto de uso, algumas acabaram sendo descartadas, pois não resultavam nas hipóteses levantadas anteriormente. Assim, foi confirmado um total de 7 (sete) neologismos criados pelo Papa, outros 15 (quinze) neologismos empregados, mas não criados por Bergoglio, além de outros vocábulos e frases que caracterizam regionalismos latino-americanos e coloquialismos. Esses resultados serão tratados na próxima seção.

\section{Análise dos bergoglismos e suas respectivas traduções}

Para início da análise, serão consideradas as criações de Jorge Bergoglio, já referido como um Papa neologista, que reinventa o Latim, o Espanhol e o Italiano ${ }^{7}$. Suas criações exploram de maneira inovadora o léxico religioso, teológico/filosófico e popular.

Partindo dos neologismos verbais, foi observada sua formação dentro de processos usuais da língua espanhola, ou seja, cria-se uma matéria nova a partir de outra já existente. 
Basicamente, os neologismos verbais do Papa que foram identificados no corpus consistem num fenômeno morfológico de derivação, em que de um substantivo ou adjetivo é criado um verbo, por acréscimo de sufixo, como ilustrado no quadro a seguir:

Quadro 2- Neologismos verbais

\begin{tabular}{|c|c|c|}
\hline & Corpus em espanhol (TO) & Corpus em português (TT) \\
\hline$(1)$ & Jesús no buscaba «doctorear» ${ }^{8}$. & Jesus não procura «doutorear». \\
\hline$(2)$ & $\begin{array}{l}\text { Quiero invitarlos hoy a estar en primera } \\
\text { línea, a primerear en todas las } \\
\text { iniciativas. }\end{array}$ & $\begin{array}{l}\text { Desejo convidar-vos hoje a estar na } \\
\text { vanguarda, a "primeirear" em todas as } \\
\text { iniciativas. }\end{array}$ \\
\hline$(3)$ & $\begin{array}{l}\text { Una fe que se ha hecho vida, una vida } \\
\text { que se ha hecho esperanza y una } \\
\text { esperanza que las lleva a primerear en la } \\
\text { caridad. }\end{array}$ & $\begin{array}{l}\text { Uma fé que se fez vida, uma vida que se } \\
\text { fez esperança e uma esperança que vos } \\
\text { leva a "primeirear" na caridade. }\end{array}$ \\
\hline$(4)$ & $\begin{array}{l}\text { Sí, al igual que Jesús, sigan } \\
\text { primereando en el amor. }\end{array}$ & $\begin{array}{l}\text { Sim, como Jesus, continuem a } \\
\text { "primeirear" no amor. }\end{array}$ \\
\hline
\end{tabular}

Elaboração: Novodvorski e Miranda

Em (1), Bergoglio usa como base o substantivo doctor (doutor) ao qual acrescenta o sufixo -ear, formando assim o neologismo doctorear. Essa construção indica que Jesus não se fazia de mestre ou doutor, nem pretendia falar de maneira magistral, mas que se expressava de modo simples e acessível aos letrados e iletrados. Doutorear também remete ao título de doutor, a quem possuiria um elevado conhecimento acadêmico em determinada matéria; contudo, o uso dado no discurso papal é de prosódia negativa. Isto é, no caso em questão, o Papa quer passar uma ideia sobre Jesus, representando-o como um ser simples, que se manifesta de jeito modesto, ensinando e catequizando com clareza e humildade, sem títulos.

Pelo viés da Avaliatividade, em termos atitudinais, observa-se nessa criação um Julgamento de estima social, em que o Papa se posiciona criticamente, provavelmente com relação àqueles que fariam ciência dos ensinamentos de Jesus, contrastando o que seria ensinar com simplicidade aos conhecimentos sofisticados que teria um doutor e que, consequentemente, ensinaria de modo complexo ou difícil. Tanto a criação por derivação quanto a marca de Avaliatividade também foram representadas na versão em português. A respeito da tradução, cabe comentar que a escolha também foi pela criação do neologismo em língua portuguesa, traduzindo a palavra de modo literal, contribuindo para o público alvo do TT receber a mesma impressão de quem lê o TO. Essa técnica é chamada de decalque.

Nos fragmentos (2) e (3), o processo de criação dos neologismos segue o mesmo modelo do anterior, com a diferença de que a derivação toma por base um adjetivo, o vocábulo primero, ao qual é acrescentado o sufixo -ear, resultando no verbo primerear. Do 
mesmo modo, a tradução por decalque parte da palavra primeiro e acrescenta o sufixo -ear, produzindo o verbo por neologismo: primeirear.

Essa criação expressa o significado de 'tomar a iniciativa', 'adiantar-se', 'ser o primeiro' a se dispor a evangelizar, fazer caridade, perdoar, amar, cumprir com os valores cristãos. Também, assim como no primeiro exemplo, este bergoglismo imprime características atitudinais de Julgamento; mas, desta vez, o vocábulo primerear denota uma estima social de valor positivo.

Em (4), Jorge Bergoglio flexiona sua própria criação, em que primerear é utilizada no gerúndio: primereando. Entretanto, essa forma não foi traduzida para a língua portuguesa com um gerúndio, a escolha tradutória foi pela utilização do neologismo verbal no infinitivo. Apesar de a escolha tradutória não ser literal, entende-se que a equivalência foi mantida, pois o aspecto de habitualidade expresso em língua espanhola pela perífrase seguir + gerúndio em "sigan primereando" também está presente na construção portuguesa continuar a + infinitivo com "continuem a primeirear".

O quadro 3, a seguir, apresenta excertos tomados do corpus com adjetivos e 104 substantivos criados, a partir de uma base nominal:

Quadro 3 - Neologismos com adjetivos e substantivos

\begin{tabular}{|c|l|l|}
\hline & \multicolumn{1}{|c|}{ Corpus em espanhol (TO) } & \multicolumn{1}{c|}{ Corpus em português (TT) } \\
\hline$(5)$ & $\begin{array}{l}\text { Esos santos de ayer pero también de hoy: } \\
\text { esta tierra tiene muchos, porque es una } \\
\text { terra "ensantada" }\end{array}$ & $\begin{array}{l}\text { São os Santos de ontem, mas também os } \\
\text { de hoje: esta terra tem muitos, porque é } \\
\text { uma terra "cumulada de santidade". }\end{array}$ \\
\hline$(6)$ & $\begin{array}{l}\text { Perú es una tierra "ensantada". } \\
\text { O Perú9 é uma terra "cumulada de } \\
\text { santidade". }\end{array}$ \\
\hline$(7)$ & $\begin{array}{l}\text { Pedro/la comunidad abatida, } \\
\text { misericordiada y transfigurada. }\end{array}$ & $\begin{array}{l}\text { Pedro-comunidade abatida, tratada com } \\
\text { misericórdia. }\end{array}$ \\
\hline$(8)$ & $\begin{array}{l}\text { Pedro misericordiado y la comunidad } \\
\text { misericordiada }\end{array}$ & $\begin{array}{l}\text { Pedro tratado com misericórdia e a } \\
\text { comunidade tratada com misericórdia. }\end{array}$ \\
\hline$(9)$ & $\begin{array}{l}\text { La Iglesia que fue herida por su pecado, } \\
\text { misericordiada por su Señor. }\end{array}$ & $\begin{array}{l}\text { A Igreja que foi ferida pelo seu pecado, } \\
\text { foi cumulada de misericórdia. }\end{array}$ \\
\hline$(10)$ & $\begin{array}{l}\text { La risa nos salva del neopelagianismo } \\
\text { "autorreferencial y prometeico de quienes } \\
\text { en el fondo sólo confían en sus propias } \\
\text { fuerzas y, se sienten superiores a otros". }\end{array}$ & $\begin{array}{l}\text { O riso salva-nos do neopelagianismo } \\
\text { "autorreferencial e prometeico de quem, } \\
\text { no fundo, só confia nas suas próprias } \\
\text { forças e se sente superior aos outros". }\end{array}$ \\
\hline
\end{tabular}

Elaboração: Novodvorski e Miranda

Nos exemplos (5) e (6), a palavra "santa" é tomada como base, sendo acrescentado primeiro o prefixo -en e, depois, o sufixo -ada, resultando num caso de derivação parassintética. O prefixo é de origem grega e designa uma posição interior, de movimento 
para dentro e/ou revestimento. Assim, entende-se ao falar que o Peru é uma terra "ensantada", que tem santos "dentro" dela, ou seja, que está recheado de santidade. O sufixo - $a d a$, de origem latina, designa multidão/conjunto e quantidade/medida, como criançada ou colherada. Dessa forma, esse sufixo na palavra "ensantada" denota uma grande quantidade de santos, estar cheia de santos.

Em termos avaliativos, observa-se na criação desse adjetivo uma Apreciação do tipo Reação, caracterizado pela qualidade de modo positivo, ou seja, o Papa emite ver com bons olhos a região descrita, fazendo uma boa avaliação desse local (Peru).

A tradução, por sua vez, opta pela descrição do neologismo utilizado no TO e não cria outra palavra em português. Na versão do texto traduzido, ensantada aparece como “cumulada de santidade". Ambas versões guardam o mesmo sentido. Contudo, no TT não é mantida a originalidade do vocábulo, talvez por uma questão de respeito e distanciamento: o Papa Francisco teria o privilégio de fazer essas criações lexicais, mas a tradução teria o papel de torná-las mais explicativas. Ensantada poderia ser utilizada em português, mas talvez gerasse alguma dificuldade de interpretação, justificando-se, assim, a escolha tradutória.

Os fragmentos (7), (8) e (9) trazem os adjetivos, masculino e feminino, criados por sufixação a partir do substantivo misericórdia, que passa a significar alguém que recebeu misericórdia. Esse neologismo é formado pela base misericórdia, acrescida dos sufixos -ado e -ada. Esse sufixo indica a ideia de algo ou alguém "provido de"; assim, nesse caso, quem é “misericordiado" é provido de misericórdia.

Percebe-se que esse bergoglismo não é neutro, pelo contrário, carrega uma prosódia semântica positiva de Afeto. Na tradução, a opção foi pela descrição do neologismo. Então, misericordiado, do espanhol, aparece como "tratado com misericórdia", no texto traduzido. Assim como ensantada, esses neologismos não aparecem com frequência nos discursos papais, nem tampouco entraram no uso popular. Talvez por isso a escolha tenha sido pela descrição do vocábulo, com uma frase explicativa mais compreensível para contexto de chegada.

Já em (10), a formação do substantivo ocorre por derivação parassintética. O prefixo neo-, do grego, se refere a algo novo, enquanto o sufixo -ismo (também grego) pode designar uma religião ou uma corrente ideológica (entre outras possibilidades). Pode-se inferir que o Papa se refere a uma nova versão do Pelagianismo, "doutrina de convicção dos pelagianos, segundo a qual o homem era totalmente responsável por sua própria salvação e que 
minimizava o papel da graça divina" (HOUAISS, 2009). Essa doutrina é relativa ao monge inglês Pelagio, que viveu no século V.

Se considerado o contexto em que esse discurso papal foi dirigido aos religiosos(as) e seminaristas do norte do Peru, compreende-se que a criação lexical neopelagianismo é caracterizada por um Julgamento negativo de estima social do tipo tenacidade, como uma crítica ao individualismo ou a uma eventual diminuição do poder divino, que enxergaria o homem como dependente apenas de si mesmo para alcançar a salvação. Ao contrário, o Papa quer fazer com que os religiosos entendam a salvação como uma graça também recebida de Deus e não dependente apenas das próprias forças humanas.

Por ser uma palavra também empregada pelo Papa em carta oficial ${ }^{10}$, infere-se que a tradução mantém o neologismo do texto original, fazendo uso do empréstimo de tal substantivo. O TT mantém a equivalência e aponta para a importância da expressão, uma vez que está circulando nos discursos católicos, primeiro por meio do Papa, por conseguinte, blogs e páginas católicas também utilizam o vocábulo, a fim de esclarecer seu sentido, de orientar e catequizar os fiéis em relação ao discurso do Papa e a seus ensinamentos.

Por último, serão apresentados dois neologismos de composição por coordenação, quando duas palavras se complementam e formam um sentido único:

Quadro 4 - Neologismos de composição por coordenação

\begin{tabular}{|c|l|l|}
\hline & \multicolumn{1}{|c|}{ Corpus em espanhol (TO) } & \multicolumn{1}{|c|}{ Corpus em português (TT) } \\
\hline A todas las personas que no sólo con & $\begin{array}{l}\text { A todas as pessoas que, não só com } \\
\text { medicamentos mas com a a } \\
\text { medicamentos sino con "la } \\
\text { cariñoterapia" ayudan a que este tiempo } \\
\text { sea vivido con mayor alegría. Tan } \\
\text { importante "la cariñoterapia". }\end{array}$ & $\begin{array}{l}\text { "carinhoterapia", ajudam para que este } \\
\text { tempo seja vivido com maior alegria. } \\
\text { Muito importante a "carinhoterapia"! }\end{array}$ \\
\hline Dale fuerza con la escucha, esa & $\begin{array}{l}\text { Dá-lhe força com as tuas palavras, dá- } \\
\text { ledicina que se va olvidando: la } \\
\text { "escuchoterapia". Dejalo hablar, dejalo } \\
\text { "escuch a escuta (eis uma } \\
\text { que te cuente. }\end{array}$ & $\begin{array}{l}\text { medicina que está a ser esquecida: a } \\
\text { "escutoterapia"). Deixa-o falar, deixa } \\
\text { que desabafe. }\end{array}$ \\
\hline
\end{tabular}

Elaboração: Novodvorski e Miranda

No fragmento (11), o Papa une dois substantivos cariño e terapia com o objetivo de criar uma palavra com sentido único, assim formam cariñoterapia. Esse neologismo significa dar um abraço, fazer companhia, dedicar um tempo a alguém, dizer "te amo", ou seja, oferecer carinho a quem necessita. Essas manifestações são vistas como uma terapia alternativa, prevenindo e/ou ajudando no processo de cura das enfermidades. 
A tradução opta pela utilização do neologismo para o texto em português com carinhoterapia, mantendo o sentido e a equivalência. Assim como no texto original, as criações e respectivas traduções em ambos os exemplos são marcadas pelo Afeto positivo do tipo Felicidade, que imprime a sensibilidade de amar, gostar, estar contente.

Da mesma forma que o primeiro exemplo, "escuchoterapia" é uma composição por coordenação. Essa criação neológica significa proporcionar uma comunicação empática, como terapia que consiste em saber escutar, com paciência, consciência e sabedoria, como oferecimento ajuda a pessoas em sofrimento por meio da escuta. A escolha tradutória escutoterapia é uma tradução literal do neologismo, em que se observa também a equivalência em termos atitudinais, como manifestação de Afeto positivo.

Todos os neologismos analisados nesta seção foram encontrados no corpus de estudo, formado pelos discursos realizados nas viagens do Papa Francisco a países de fala espanhola. Outras criações neológicas do Papa serão objeto de análise em futuras publicações. Por outro lado, a análise feita apenas a partir de alguns dos discursos do Papa possibilitou a observação da riqueza da criatividade lexical do Papa Francisco, que confirma as informações veiculadas em jornais com relação a seu linguajar rico em neologismos.

\section{Considerações finais}

Foram analisados, neste artigo, alguns aspectos da criatividade lexical do Papa Francisco, no âmbito do que foi dado a conhecer como bergoglismos, mais especificamente nos discursos realizados durante as viagens a países hispanófonos. No corpus selecionado para esta pesquisa, percebe-se que os neologismos de Bergoglio ocorrem por derivação, a partir do acréscimo de afixos como em primerear ou ensantada, este último vocábulo por formação parassintética.

As traduções dos neologismos muitas vezes ocorreram por decalque, como em primeirear e primeireando, com exceção de alguns vocábulos em que, talvez pela pouca recorrência no uso, a opção tradutória tenha sido pela explicação, como em cumulada de santidade para a tradução de ensantada. Por outro lado, a análise contrastiva das marcas atitudinais presentes nos bergoglismos, por meio do sistema da Avaliatividade (MARTIN; WHITE, 2005), mostrou-se também produtiva. Foi possível observar que o Papa Francisco faz Julgamentos, Apreciações e registra marcas de Afeto em suas criações lexicais, estabelecendo posicionamentos críticos tanto positivos quanto negativos. 
Cabe salientar, também, que a descrição dos procedimentos metodológicos empregados neste trabalho possibilita sua replicação em futuras pesquisas. Os princípios da LSF, aplicados à observação dos fatos da língua, com suporte da abordagem e metodologia da Linguística de Corpus, demonstraram ser um conjunto eficaz de ferramentas disponíveis para a pesquisa descritiva. Por meio do construto teórico e dos procedimentos adotados neste artigo, espera-se poder contribuir para a ampliação das pesquisas e investigações em criatividade lexical, em interface com a Avaliatividade e os Estudos da Tradução, no âmbito dos estudos contrastivos, envolvendo as línguas espanhola e portuguesa.

\section{REFERÊNCIAS BIBLIOGRÁFICAS}

ALVES, Ieda Maria. Neologismo: Criação Lexical. 1 ed. São Paulo: Editora Ática, 1990.

BERBER SARDINHA, T. Lingüística de Corpus. Barueri: Manole, 2004.

GALLARDO PAÚLS, Beatriz. Comentario de textos conversacionales: I. De la teoría al comentario. Madrid: Arco Libros, 1998.

108 HALLIDAY, Michael. Language as social semiotic: The social interpretation of language and meaning. London: Edward Arnold, 1978.

HOUAISS, Antônio. Dicionário eletrônico Houaiss da língua portuguesa. Versão 3.0, 2009.

HURTADO ALBIR, Amparo. Traducción y Traductología: Introducción a la Traductología. $4^{\mathrm{a}}$ ed. Madrid: Cátedra, 2008.

MARTIN, Jim R.; WHITE, Peter R. R. The Language of Evaluation: appraisal in English. London: Palgrave, 2005.

NOVODVORSKI, Ariel. A representação de atores sociais nos discursos sobre o ensino de espanhol no Brasil em corpus jornalístico. 2008. Dissertação (Mestrado em Estudos Linguísticos) - Faculdade de Letras, Universidade Federal de Minas Gerais, Belo Horizonte, Minas Gerais, 2008.

NOVODVORSKI, Ariel. Estilo das traduções de Sergio Molina de obras de Ernesto Sabato: um estudo de corpora paralelos espanhol/português. 2013. Tese (Doutorado em Estudos Linguísticos) - Faculdade de Letras, Universidade Federal de Minas Gerais, Belo Horizonte, Minas Gerais, 2013.

PARODI, Giovanni. Lingüística de Corpus: de la teoría a la empiria. Madrid: Iberoamericana / Vervuert, 2010.

PERINI, Mário. A. Princípios de lingüística descritiva: introdução ao pensamento gramatical. São Paulo: Parábola Editorial, 2006. 
SCOTT, Mike. WordSmith Tools (6.0) [Programa computacional]. Liverpool: Lexical Analysis Software, 2012. Disponível em:

http://www.lexically.net/wordsmith/version6/index.html. Acesso em: 5 out. 2019.

WHITE, Peter. R. R. Un recorrido por la teoría de la valoración (Teoría de la valoración). The Appraisal Website. 2000. Disponível em:

http://www.grammatics.com/appraisal/spanish_tr/spanishtranslation-appraisaloutline.pdf.

Acesso em: 5 out. 2019.

\footnotetext{
* Ariel NOVODVORSKI - Doutor (2013) e Mestre (2008) em Estudos Linguísticos pela Universidade Federal de Minas Gerais. Licenciado em Letras Português/Inglês (2005) pela Universidade Presidente Antônio Carlos. Professor na Universidade Federal de Uberlândia (UFU). Uberlândia, Minas Gerais, Brasil.

Currículo acadêmico: http://lattes.cnpq.br/2882362453894798

ORCID: https://orcid.org/0000-0003-1370-8334

E-mail: arivorski@ufu.br

** Hellen Betin MIRANDA - Mestranda em Estudos Linguísticos na Universidade Federal de Uberlândia. Graduada em Letras - Espanhol (2015) pela mesma instituição. Uberlândia, Minas Gerais, Brasil.

Currículo acadêmico: http://lattes.cnpq.br/2054974125228531

ORCID: https://orcid.org/0000-0002-2579-6418

E-mail: hellenbetinm@gmail.com

1 Disponível em: http://www.lagaceta.com.ar/nota/569710/mundo/bergoglismos-neologismos-francisco-atraenatencion.html. Acesso em: 6 out. 2019.

${ }^{2}$ Disponível em: http://www.lanacion.com.ar/1643494-bergoglismos-el-lexico-que-impacta-a-todos. Acesso em: 6 out. 2019.

${ }^{3}$ Os exemplos colocados entre aspas foram retirados o livro Neologismo, de Ieda Maria Alves, 1990. Os demais exemplos, grafados em itálico, foram tomados do nosso corpus de estudo, ou seja, são neologismos criados ou empregados pelo Papa Francisco durante as falas de seus discursos em espanhol.

${ }^{4}$ Este fragmento não é uma tradução ipsis litteris do livro, mas sim uma leitura e adaptação livre dos autores deste trabalho.

5 Disponível em: http://w2.vatican.va/content/francesco/pt/travels/2017/outside.index.html. Acesso em: 6 out. 2019.

${ }^{6}$ Disponível em: https://www.corpusdelespanol.org. Acesso em: 6 out. 2019.

7 Disponível em: http://www.ihu.unisinos.br/noticias/526772-bergoglismo-o-lexico-do-papa-que-surpreende-atodos. Acesso em: 6 out. 2019.

${ }^{8}$ As aspas que se encontram no início e no final de algumas palavras nos quadros desta seção são advindas do texto original, apenas os termos sublinhados foram marcações de nossa autoria.

${ }^{9}$ Manteve-se a escrita original do corpus.

${ }^{10}$ Em fevereiro de 2018 o Papa Francisco publicou a Carta "Placuit Deo" - Aprouve a Deus - em que esclarece o significado da verdadeira salvação cristã e usa o neologismo "neopelagianismo", referindo-se a este como contrário à salvação. Este gênero, também chamado de Encíclica, é comumente dirigido a bispos do mundo inteiro e estes têm o dever de passar as informações aos leigos. Geralmente há doutrina, incentivo à uma devoção e/ou orientações e correções sobre condutas. Disponível em: http://cleofas.com.br/a-salvacao-de-cristo-erecebida-na-igreja/. Acesso em: 6 out. 2019.
} 